\title{
PRÁTICA DE ENSINO BASEADA EM APRENDIZAGEM ATIVA: EXPLORANDO A ACESSIBILIDADE EM ALGUNS ESPAÇOS DA UNEB
}

Telma Dias Silva dos Anjos - telmadias@uneb.br

Tânia Regina Dias Silva Pereira - tanreg.uneb@ gmail.com

Universidade do Estado da Bahia - UNEB, Departamento de Ciências Exatas e da Terra DCET I

Rua Silveira Martins, 2555, Cabula/ Narandiba

CEP: 41192-010 - Salvador - Bahia

Claudia Dias Silva - cldsilva@uneb.br

Universidade do Estado da Bahia - UNEB, Departamento de Educação - DEDC I

Rua Silveira Martins, 2555, Cabula/ Narandiba

CEP: 41192-010 - Salvador - Bahia

Tatiana Dias Silva - tdsilva@uneb.br

Universidade do Estado da Bahia - UNEB, Departamento de Educação - DEDC X

Avenida Kaikan, s/n, Kaikan

CEP: 45992-255 - Teixeira de Freitas - Bahia

Resumo: Nos últimos anos percebemos significativas mudanças nas abordagens que fundamentam o processo de ensino e aprendizagem. Nesse contexto, podemos destacar a aprendizagem ativa, que apresenta como premissa a participação efetiva dos discentes para a realização de um trabalho interativo e colaborativo. Com base nas atuais concepções didáticas, e visando contribuir para a construção de um processo de ensino e aprendizagem significativo e contextualizado, propusemos aos discentes de Engenharia de Produção Civil a realização de uma atividade investigativa que ultrapassou as paredes da sala de aula. $O$ objetivo principal da experiência de ensino foi desenvolver um estudo sobre acessibilidade, buscando identificar as adequações realizadas no espaço físico da Universidade para atender as normas da ABNT 9050:2015. A metodologia utilizada possibilitou explorar o campus universitário através de visitas aos quatro departamentos, das portarias de acesso e da biblioteca do Campus I da UNEB. O plano de atividades envolveu estudo prévio do arcabouço teórico que fundamentou a pesquisa, visita local, medições, realização de entrevista, registro fotográfico, elaboração de artigo e apresentação de seminário discutindo os resultados do trabalho de campo. Os resultados apresentados pelos discentes mostraram o engajamento dos grupos na realização da experiência, bem como a maior compreensão sobre o tema abordado na atividade através da relação teoria-prática.

Palavras-chave: Aprendizagem Ativa. Acessibilidade. Engenharia. Prática de ensino. Universidade. 


\section{INTRODUÇÃo}

O presente trabalho tem como objetivo principal descrever uma prática de ensino desenvolvida na disciplina Desenho de Construção Civil que é oferecida aos discentes do terceiro semestre do curso de Engenharia de Produção Civil da Universidade do Estado da Bahia - UNEB. A atividade de ensino foi orientada pela implementação de uma proposta de metodologia de aprendizagem ativa que proporcionou aos estudantes em formação o estudo do conteúdo programático Acessibilidade de forma dinâmica e interativa, levando-os à uma análise reflexiva sobre a sua atuação profissional. Os estudantes puderam, a partir da problematização da realidade do local onde ocorrem os estudos, das discussões sobre o arcabouço teórico que fundamenta o conteúdo estudado, da realização de entrevistas com alunos de outros cursos ofertados pela instituição, da socialização das atividades através de seminários e da interação mútua entre os atores envolvidos no processo - docente e discentes - identificar a funcionalidade e aplicabilidade desse aprendizado no exercício de sua prática profissional.

O documento elaborado pelo Conselho Nacional de Educação/Câmara de Ensino Superior, Resolução CNE/CES No 02/2019, institui as Diretrizes Curriculares Nacionais - DCNs para o funcionamento dos cursos de Engenharia. Esse instrumento normativo apresenta as premissas que devem servir de orientação à organização, ao desenvolvimento e à avaliação dos referidos cursos pelos Sistemas de Educação Superior do país.

[...] definir modelos de educação que estimulem a experimentação e deem protagonismo aos alunos no processo de aprendizagem e desenvolvimento de suas competências técnicas e socioemocionais. Isso implica, entre outras coisas, em valorizar atividades que instiguem os jovens a desenvolver projetos e soluções com base sólida e responsabilidade, explorar a interdisciplinaridade, dominar tecnologias digitais, construir visões sistêmicas, cultivar a criatividade, trabalhar em equipe e exercitar a liderança (CNI, 2020, p.10).

As Diretrizes também explicitam as competências que os engenheiros devem construir ao longo do processo formativo. Dentre essas competências está a de formular e conceber soluções desejáveis de engenharia, analisando e compreendendo os usuários dessas soluções e seu contexto, desenvolvendo a capacidade de utilizar técnicas adequadas de observação, compreensão, registro e análise das necessidades dos usuários e de seus contextos sociais, culturais, legais, ambientais e econômicos, bem como formular, de maneira ampla e sistêmica, questões de engenharia, considerando o usuário e seu contexto, concebendo soluções criativas, bem como o uso de técnicas adequadas (Art. $4^{\circ}$, incisos I e II).

Por isso, as novas Diretrizes propõem uma formação com base em um conjunto de experiências práticas e ativas de aprendizagem, vinculadas a conceitos e conhecimentos diversos, incorporados pelo estudante ao longo de um processo formativo do qual é agente fundamental (CNI, 2020, p.19).

A atividade de cunho investigativo ora apresentada se articula às DCNs constituindo-se numa estratégia de ensino adotada durante o semestre letivo 2019.2 que buscou, dentre outras finalidades, estabelecer uma relação dialógica entre teoria e prática suscitando no estudante de engenharia, desde o início do seu processo formativo, a necessidade de conhecer o contexto de aplicação dos conteúdos estudados, atentando-se para a análise e compreensão dos usuários dos projetos e soluções apresentadas à sociedade. 
Em consonância com essa finalidade, o conteúdo programático abordado foi a Acessibilidade. Esse tema, que apresenta grande relevância social e política, vem recebendo cada vez mais atenção nas discussões acerca do desenvolvimento social e humano, aparecendo como um dos pressupostos centrais das políticas públicas que visam a democratização de acesso, de permanência e da inclusão de crianças, jovens e adultos no sistema formal de ensino, considerando seus diferentes níveis.

Com vistas a proporcionar maior entendimento e clareza da experiência realizada, esse texto foi organizado em quatro seções. Na primeira, denominada Introdução, consta uma breve apresentação da experiência, o objetivo da atividade, a metodologia adotada e a justificativa da escolha do conteúdo e do caminho metodológico usado. Em seguida, na seção Fundamentação teórica, são abordados os temas Aprendizagem Ativa e Acessibilidade, que nortearam a experiência realizada. Posteriormente, é apresentado o relato da experiência com descrição do plano de atividades proposto, bem como a execução das atividades pelos discentes. Por fim, as Considerações finais apresentam reflexões e contribuições proporcionadas pela atividade realizada com os estudantes do curso de engenharia.

\section{FUNDAMENTAÇÃO TEÓRICA}

Nessa sessão abordaremos os conceitos de Aprendizagem Ativa e Acessibilidade, temáticas que possibilitaram o desenvolvimento da prática realizada.

\subsection{Aprendizagem Ativa}

Para Moran "a aprendizagem é ativa e significativa quando avançamos em espiral, de níveis mais simples para mais complexos de conhecimento e competência em todas as dimensões da vida" $(2018$, p. 2). A proposta é que o aluno vivencie de forma antecipada, durante o curso, problemas e situações reais que vivenciarão na vida profissional. Quanto mais exemplos do cotidiano, melhor o aprendizado.

Diferente dos métodos tradicionais, que privilegiam a transmissão de informações pelos professores, a aprendizagem ativa prioriza maior envolvimento do aluno, uma vez que é baseada em competências cognitivas, pessoais e sociais, que não se adquirem da forma convencional e que exigem proatividade, colaboração, personalização e visão empreendedora. É uma parceria entre professor e aluno na busca pelo conhecimento.

A proposta é que o estudante esteja no centro do processo de aprendizagem, participando ativamente e sendo responsável pela construção do seu conhecimento enquanto o professor é o mediador e estimulador do processo de ensino-aprendizagem. Seu principal objetivo é incentivar o aluno a aprender de forma autônoma e participativa, a partir de problemas e situações reais. Para José Moran (2015, p. 17),

As metodologias precisam acompanhar os objetivos pretendidos. Se queremos
que os alunos sejam proativos, precisamos adotar metodologias em que os
alunos se envolvam em atividades cada vez mais complexas, em que tenham
que tomar decisões e avaliar os resultados, com apoio de materiais relevantes.
Se queremos que sejam criativos, eles precisam experimentar inúmeras
possibilidades de mostrar sua iniciativa.

Dessa forma, o aluno precisa ser participante ativo no seu processo de aprendizagem, onde o professor atua como orientador, supervisor e facilitador. Barbosa e Moura (2013, p. 55) afirmam que a "aprendizagem ativa ocorre quando o aluno interage com o assunto em estudo 
(ouvindo, falando, perguntando, discutindo, fazendo e ensinando) sendo estimulado a construir o conhecimento ao invés de recebê-lo de forma passiva do professor".

Corroborando com esta opinião, Mineiro e D’Ávila colocam que o professor precisa utilizar artifícios para eliminar o "ciclo vicioso reprodutivista" e, para que isso aconteça, deve começar mudando sua prática de ensino buscando utilizar meios que alcance o aprendizado do aluno. As autoras afirmam que uma maneira de atingir esse objetivo é:

Dando-lhe "trabalho" para pensar, para ler, para analisar. Construir situações de aprendizado áulicas (e para fora da sala de aula também) inserindo nelas dispositivos que fomentam a real mediação cognitiva. Metaforicamente falando, nada de refinar demais o alimento, assim ele perde nutrientes... É preciso que o aluno habitue (ou re-habitue) seu organismo (mecanismos cognitivos) a processar o alimento ("conhecimento") (MINEIRO; D’ÁVILA, 2020, p. 152).

Há diversas técnicas para a aprendizagem ativa, entre as quais: a sala de aula invertida, onde o aluno pesquisa as informações básicas sobre um tema ou problema para iniciar-se no assunto, partindo dos conhecimentos prévios e ampliando-os com referências dadas pelo professor; a aprendizagem baseada na investigação e em problemas, que utiliza situaçõesproblema como ponto de partida para a construção de novos conhecimentos; a aprendizagem baseada em projetos, que tem como objetivo a entrega de um produto que pode ser um relatório das atividades realizadas, um protótipo de solução concebida ou um plano de ação a ser implementado na comunidade local; a aprendizagem por histórias e jogos, aquela em que a aprendizagem acontece a partir de histórias contadas (narrativas) e histórias em ação (histórias vividas e compartilhadas); a instrução por pares, que tem como perspectiva que os alunos aprendam uns com os outros, exercendo o papel de instrutores ou professores; o movimento maker, centrado no conceito de aprendizagem experimental, que enfatiza a relevância de aprender fazendo, a projeção e a construção de artefatos e a fabricação digital; Design Thinking, processo composto por etapas que preveem a escuta, a observação, a investigação, a projeção de soluções, a prototipagem e a implementação das melhores soluções criadas; entre outras. Destacamos, entretanto, que o sucesso de qualquer metodologia de aprendizagem ativa depende de uma mudança na atuação do professor em sala de aula (CAVALCANTI; FILATRO, 2018; MORAN, 2018).

Pensar em aprendizagem ativa é o ponto de partida para avançar nos processos mais elaborados de reflexão, de integração cognitiva, de generalização, de reelaboração de novas práticas. "Para tanto, os diálogos promovidos em um ambiente de aprendizagem ativa devem ser conduzidos de forma a proporcionar a todos os participantes a tomada de consciência das ações, que levem a uma aprendizagem duradoura" (FILHO et al, 2019, p.35). O uso de metodologias ativas promove uma transformação na concepção do aprendizado por proporcionar ao aluno a oportunidade de pensar de maneira diferente em possíveis soluções para resolver problemas conectando ideias que, em princípio, parecem desconectadas (MORAN, 2015).

\subsection{Acessibilidade}

O Decreto $\mathrm{n}^{\circ}$. 6.949, publicado em 25 de agosto de 2009, tornou público à sociedade brasileira a Convenção Internacional sobre os Direitos das Pessoas com Deficiência e seu Protocolo Facultativo assinados em Nova York, em 30 de março de 2007. A referida Convenção define Pessoas com Deficiência $(\mathrm{PcD})$ como "aquelas que têm impedimentos de longo prazo de natureza física, mental, intelectual ou sensorial, os quais, em interação com diversas 
barreiras, podem obstruir sua participação plena e efetiva na sociedade em igualdades de condições com as demais pessoas" (BRASIL, 2009).

A discussão sobre a garantia de acesso das PcD aos diversos espaços que lhes proporcione condições que favoreçam seu bem-estar e interatividade social é tema recorrente nos diferentes campos de estudos científicos. Nessa direção, o aprofundamento dos estudos e das reflexões em torno do tema possibilitaram que a atenção destinada a Acessibilidade superasse os limites espaciais, fazendo com que o entendimento voltado para "a concepção de objetos, equipamentos e ao espaço físico para a $\mathrm{PcD}$, fossem direcionados de forma a incluir a maioria das pessoas, independente de limitações físicas, cognitivas ou sensoriais" (GOMES; EMMEL, 2020, p.164).

A fim de preparar os profissionais que exercem atividades laborais que atendam às necessidades das PcDs, o estudo sobre o tema passou a ser contemplado nos projetos pedagógicos dos cursos de formação profissional em diferentes áreas, dentre elas, a área de Engenharia.

Acessibilidade é um dos temas mais atuais e importantes no setor da construção civil. É dever da sociedade lembrar que idosos, obesos, gestantes, usuários de muletas, crianças, deficientes auditivos e visuais devem ser considerados no planejamento da edificação, e não apenas o cadeirante (SIENGE, 2020, p.4).

No curso de graduação em Engenharia de Produção Civil oferecido pela UNEB, o tema Acessibilidade perpassa por vários componentes curriculares, porém, nesse estudo, vamos discuti-lo no âmbito da disciplina Desenho de Construção Civil. O material basilar dos estudos sobre o tema em questão é a Norma Técnica NBR 9050/2015, apresentada pela Associação Brasileira de Normas Técnicas - ABNT. Essa norma trata da Acessibilidade a edificações, mobiliário, espaços e equipamentos urbanos, visando facilitar o trânsito de pessoas com limitação de mobilidade e sensação.

$\mathrm{O}$ conceito de acessibilidade que embasou a experiência desenvolvida foi o mesmo apresentado pela citada norma. De acordo com esse documento, o termo acessibilidade pode ser definido como:

[...] possibilidade e condição de alcance, percepção e entendimento para utilização, com segurança e autonomia, de espaços, mobiliários, equipamentos urbanos, edificações, transportes, informação e comunicação, inclusive seus sistemas e tecnologias, bem como outros serviços e instalações abertos ao público, de uso público ou privado de uso coletivo, tanto na zona urbana como na rural, por pessoa com deficiência ou mobilidade reduzida (ABNT 9050/2015).

Por conseguinte, não podemos perder de vista que a discussão sobre acessibilidade é atravessada por outros aspectos que superam as questões das edificações ou do urbanismo. A acessibilidade é um dos produtos projetados pela sociedade que visa possibilitar a interação entre a PcD e a sociedade, promovendo a inclusão social desses indivíduos, e o exercício da cidadania de todos os atores envolvidos nesses processos. Santos (2004, p.10) destaca que "a acessibilidade é um dos principais fatores que rege a inter-relação entre a sociedade e a Pessoa com Deficiência $(\mathrm{PcD})$, influenciando vários aspectos ligados a seus direitos enquanto cidadão".

Por fim, faz-se necessário considerar que a partir da importância dedicada pela população ao assunto, as discussões sobre acessibilidade também consideram que para facilitar a inter- 
relação social, o espaço acessível deve ser de fácil compreensão, permitindo ao usuário se locomover, comunicar-se, além de usufruir deste espaço com segurança, conforto e autonomia, independentemente de suas restrições (GOMES; EMMEL, 2020).

\section{RELATO DA EXPERIÊNCIA DESENVOLVIDA}

Exclusivamente com a finalidade de propiciar maior entendimento e apreensão da experiência, organizamos essa seção em duas subseções, quais sejam: Lócus onde foi realizada a pesquisa e relato da experiência.

\subsection{Lócus onde foi realizada a pesquisa}

A UNEB é a maior instituição pública de ensino superior da Bahia, pois está presente geograficamente em todas as regiões do Estado. É estruturada no sistema multicampi e mantida pelo Governo do Estado através da Secretaria de Educação. Possui 29 Departamentos distribuídos em 24 campi: o Campus I, sediado em Salvador, e os demais em municípios de médio e grande porte.

No Campus I estão instalados os Departamentos de Educação (DEDC), de Ciências Exatas e da Terra (DCET), de Ciências Humanas (DCH) e de Ciências da Vida (DCV). O campus de Salvador foi o primeiro a ser criado pela instituição superior com o propósito de cumprir a sua missão: produzir, difundir, socializar e aplicar o conhecimento nas diversas áreas do saber (UNEB, 2020).

No DCET I são oferecidos cursos de Licenciatura (em Química e em Física), Tecnólogo (Jogos Digitais) e de bacharelado (em Design, Sistemas de Informação, Urbanismo e Engenharia de Produção Civil).

A pesquisa aqui apresentada foi realizada no semestre 2019.2, com discentes do curso de Engenharia de Produção Civil, no componente curricular ENG 031 - Desenho de Construção Civil, ministrado no terceiro período. É uma disciplina de 75 horas/aula, que apresenta a acessibilidade como um dos conteúdos programáticos.

\subsection{Relato da experiência}

Com a finalidade de propiciar maior entendimento e apreensão da experiência, organizamos essa seção em três subseções, quais sejam: planejamento da atividade, execução da atividade e considerações dos discentes sobre a experiência.

\section{Planejamento da atividade}

Para atender aos objetivos propostos, a atividade foi dividida em três etapas: a primeira explorou o conhecimento da Norma da ABNT, a segunda o cumprimento desta norma nos espaços físicos da universidade e a terceira se fixou na apresentação do material coletado.

A metodologia foi empregada com o propósito de incentivar o discente a pensar e agir de forma crítica, preparando-o para enfrentar as mudanças na sociedade, e para desenvolver habilidades na resolução de problemas tanto simples quanto complexos, seguindo, também, as orientações das DCNs, que determinam que "Deve ser dada preferência a metodologias que desenvolvam no estudante o pensamento crítico e a capacidade de resolução de problemas numa perspectiva multidisciplinar" (CNI, 2020, p.34).

\section{Execução da atividade}

Inicialmente, foi proposto aos estudantes que pesquisassem na internet a Norma NBR 9050/2015, para, em seguida, realizarmos estudos e discussões em sala de aula a fim de que 
pudéssemos analisar e compreender os conteúdos apresentados na referida norma, o que fundamentou o trabalho de campo a ser realizado. Posteriormente, foi sugerido pelos alunos que fizéssemos uma vistoria no prédio em que estávamos, com a finalidade de verificarmos as regularidades e irregularidades deste com relação a acessibilidade, fazendo anotações de algumas características referentes ao que foi estudado.

$\mathrm{Na}$ sequência, a turma foi dividida em quatro equipes de quatro componentes e duas de três, que ficaram responsáveis por pesquisar a acessibilidade nos quatro departamentos; na biblioteca central e prédios do entorno; e nas portarias (de pedestres e de carros) do Campus I.

Os procedimentos metodológicos empregados nesta etapa foram divididos em dois estudos: 1 - Visita aos espaços previamente determinados com as equipes para verificar se os ambientes atendiam as especificações da norma; 2 - Entrevista com docentes, discentes, técnicos e pessoas com deficiência ou com mobilidade reduzida temporária, com o propósito de identificar possíveis perigos na locomoção nesses espaços pesquisados.

Os grupos analisaram a existência de rampas, guarda corpos/corrimões, corredores, escadas, sinalizadores (visuais, táteis e sonoros), vagas de estacionamento, sanitários adaptados, elevadores e o acesso até cada edificação estudada. $\mathrm{Na}$ vistoria foram utilizados como instrumentos de auxílio à pesquisa uma trena, para medir dimensão dos corredores, os espelhos e pisos das escadas, a altura do guarda corpo, a extensão necessária do corrimão etc., itens exigidos pela norma; e o aparelho celular para que, através de fotografias, comprovassem o que foi descrito acima e fundamentar o estudo.

Por fim, a terceira e última etapa foi estruturada de modo a garantir a sistematização, o registro e a socialização das informações coletadas na exploração dos espaços físicos. 1 Compilação de todas as informações obtidas e escrita de um artigo científico; 2 - Elaboração de seminário para apresentação dos resultados obtidos por cada equipe. Ao final de cada apresentação, foi feito um debate no qual os discentes questionaram, argumentaram, complementaram os assuntos ampliando, assim, o aprendizado da turma.

\section{Considerações dos discentes sobre a experiência}

Os pressupostos da aprendizagem ativa privilegiam o protagonismo dos discentes nas atividades de ensino visando a construção de uma aprendizagem significativa, contextualizada e colaborativa. Assim, os indivíduos atribuem significado e funcionalidade aos conhecimentos construídos.

A realização dessa atividade possibilitou aos discentes do curso de Engenharia de Produção Civil vivenciarem o exercício prático dos conhecimentos sobre acessibilidade estudados na NBR 9050:2015, favorecendo a reflexão sobre a importância e a representação que a profissão desempenha na sociedade. De acordo com os discentes "[...] ao se pensar em alternativas que possibilitam o avanço e maior uso da acessibilidade busca-se a engenharia como um meio moderno, transformador e necessário para que se tenha um processo de desenvolvimento e mudança no que se refere a questão da mobilidade no país" (EQUIPE 6).

Permitiu ainda o entendimento de que o uso de tal conhecimento não está limitado à sua instrumentalização para o exercício da profissão. Ele transcende o caráter técnico e assume o compromisso social com o emprego de técnicas que atendam às necessidades de uma população, neste caso, as PcDs, conforme registrado nos relatórios de atividades.

No âmbito pessoal, objetiva-se a síntese das necessidades presentes no dia a dia daqueles que dependem das normas para melhor locomoção, pois como estudantes de Engenharia de Produção Civil, esse aprendizado faz parte dos 
conteúdos apresentados na disciplina, além de ser de grande utilidade para a formação pessoal e profissional (EQUIPE 1).

Além disso, é indiscutível que os estudos, vistoria e pesquisas realizadas no decorrer do trabalho, nos proporcionaram esclarecimentos e maturidade do quão importante e essencial é a aplicação da norma de acessibilidade (NBR 9050:2015) nas construções civis (EQUIPE 3).

[...] assim, perante as situações adversas encontradas nos locais aferidos, torna-se clara a necessidade do estudo detalhado a respeito do que se considera indispensável para o bem-estar dos brasileiros portadores de deficiências que limitem sua locomoção (EQUIPE 4).

Como parte de um conjunto maior, é compreensível que nem todos os setores apresentem $100 \%$ de perfeição em suas instalações, mas por meio deste, apontamos os pontos que podem ser adequados para melhor convívio dos alunos, docentes e demais pessoas que frequentam esse local, pois, garantindo o mínimo conforto possível às pessoas com deficiência, assegura-se aos mesmos o bem maior de uma sociedade desenvolvida: a cidadania (EQUIPE 2).

Em consonância com os relatos dos discentes, é possível depreender que a metodologia da aprendizagem ativa, a partir da problematização do lócus de formação acadêmica dos discentes, também os despertou para a construção de uma responsabilidade individual e social necessárias ao enfrentamento dos desafios encontrados ao longo do exercício profissional.

\section{CONSIDERAÇÕES FINAIS}

As atividades realizadas com base em problemas e situações reais deram aos discentes a oportunidade de aprender de forma participativa, proporcionando maior envolvimento sem perder de vista sua autonomia e protagonismo, tornando-o responsável pela construção de seu conhecimento.

A partir da inserção nas atividades de campo os discentes puderam aplicar conhecimentos construídos sobre os principais assuntos estudados, e, ao serem desafiados a pesquisar e escrever, alguns superaram limitações, pois foram estimulados a ler, interpretar e refletir, promovendo mudanças no seu processo de aprendizagem. $\mathrm{O}$ trabalho em grupo proporcionou uma maior interação entre os alunos, promoveu o diálogo, incentivou o trabalho de forma colaborativa e ajudou a superar limitações.

A postura de coparticipante assumida pela professora tornou as aulas mais atrativas, interativas, pois envolveu os discentes em atividades nas quais tinham que tomar decisões e avaliar os resultados, e estes se sentiram instigados a perguntar, defender suas ideias e argumentar, aprofundando conhecimentos através da formação contextualizada e guiada pela prática.

É importante registrar que a pesquisa realizada no espaço físico da universidade teve um caráter essencialmente didático-pedagógico, pois, a maioria dos prédios do Campus I da UNEB já existia antes da publicação da NBR 9050:2015, o que vem demandando dos gestores ações no tocante às adaptações das edificações às condições de acessibilidade ao longo das últimas décadas. 


\section{Agradecimentos}

Agradecemos a todos os discentes matriculados na disciplina Desenho de Construção Civil, pelo empenho em fazer o melhor para o seu aprendizado e para o desenvolvimento da disciplina durante o semestre letivo 2019.2.

\section{REFERÊNCIAS}

ASSOCIAÇÃO BRASILEIRA DE NORMAS TÉCNICAS. NBR 9050: Acessibilidade a edificações, mobiliário, espaços e equipamentos urbanos. Rio de Janeiro, 2015.

BARBOSA, E. F.; MOURA, D. G. de. Metodologias ativas de aprendizagem na Educação Profissional e Tecnológica. B. Tec. Senac, v. 39, n. 2, p. 48-67, 2013.

BRASIL. Ministério da Educação. Conselho Nacional de Educação. Resolução CNE/CES no 2, de 24 de abril de 2019. Institui Diretrizes Curriculares Nacionais para Curso de Graduação em Engenharia. Brasília, DF, 2019.

BRASIL. Decreto $\mathbf{n}^{\circ}$ 6.949, de 25 de agosto de 2009. Promulga a Convenção Internacional sobre os Direitos das Pessoas com Deficiência e seu Protocolo Facultativo, assinados em Nova York, em 30 de março de 2007. Disponível em:

<http://www.planalto.gov.br/ccivil_03/_ato2007-

2010/2009/decreto/d6949.htm\#: :text=Decreto\%20n\%C2\%BA\%206949\&text=DECRETO\% 20N\%C2\%BA\%206.949\%2C\%20DE\%2025,30\%20de\%20mar\%C3\%A7o\%20de\%202007>. Acesso em: 05 ago. 2020.

CAVALCANTI, C. C.; FILATRO, A. Metodologias inov-ativas na educação presencial, a distância e corporativa. São Paulo: Saraiva, 2018.

CNI. Documento de apoio à implantação das DCNs do Curso de Graduação em Engenharia. Brasília, 2020. Disponível em: $<$ https://www.portaldaindustria.com.br/publicacoes/2020/6/documento-de-apoio-implantacaodas-dcns-do-curso-de-graduacao-em-engenharia/>. Acesso em: 30 jun. 2020.

FILHO, G. E.; SAUER, L. Z.; ALMEIDA, N. N. de.; VILLAS-BOAS, V. Uma nova sala de aula é possível: aprendizagem ativa na educação em engenharia. Rio de Janeiro: LTC, 2019.

GOMES, L.; EMMEL, M. L. G. Análise dos conteúdos sobre acessibilidade e desenho universal nos cursos de graduação em arquitetura e terapia ocupacional no Brasil. Caderno Brasileiro de Terapia Ocupacional, São Carlos, vol.28, $\mathrm{n}^{\circ}$ 1, jan./mar. 2020. Disponível em: $<$ https://www.scielo.br/scielo.php?script=sci_arttext\&pid=S252689102020000100164\&lng=pt\&nrm=iso >. Acesso em: 03 ago. 2020.

MINEIRO, M.; D’ÁVILA, M. C. Construindo pontes: a mediação didática lúdica no ensino superior. Revista Práxis Educacional, Vitória da Conquista, Bahia, Brasil, v. 16, n. 37, p. 146-172, Edição Especial, 2020. https://doi.org/10.22481/praxisedu.v16i37.6026. MORAN, J. M. Mudando a educação com metodologias ativas. In: Convergências Midiáticas, Educação e Cidadania: aproximações jovens. Coleção Mídias Contemporâneas, 2015. Disponível em:

<http://www2.eca.usp.br/moran/wpconteiasodolognt/uploads/2013/12/mudando_moran.pdf. > Acesso em: 31 jul. 2020. 
Metodologias Ativas para uma aprendizagem mais profunda. In: BACICH, L.; MORAN, J. (Orgs). Metodologias Ativas para uma educação inovadora: uma abordagem teórico-prática. São Paulo: Penso, 2018.

SANTOS, L. K. S. Diretrizes de arquitetura e design para adaptação da habitação de interesse social ao cadeirante. (Dissertação de mestrado). Universidade Federal do Paraná, Curitiba, (2004).

SIENGE. Acessibilidade na construção civil: obras adaptadas do início ao fim. Disponível em: https://www.sienge.com.br/thank-page-ebook-acessibilidade-na-construcao-civil/. Acesso em: 30 jun. 2020.

UNEB. Campus Salvador: conheça o campus. Disponível em: https://portal.uneb.br/salvador. Acesso em: 25 jul. 2020.

\title{
TEACHING PRACTICE BASED ON ACTIVE LEARNING: EXPLORING ACCESSSIBILITY IN SOME SPACES IN UNEB
}

\begin{abstract}
In recent years we have noticed significant changes in the approaches that underlie the teaching and learning process. In this context, we can highlight active learning, which presents as a premise the effective participation of students to carry out interactive and collaborative work. Based on the current didactic conceptions, and aiming to contribute to the construction of a meaningful and contextualized teaching and learning process, we proposed to the Civil Production Engineering students to carry out an investigative activity that went beyond the classroom walls. The main objective of the teaching experience was to develop a study on accessibility, seeking to identify the adjustments made in the physical space of the University to meet the standards of ABNT 9050: 2015. The methodology used made it possible to explore the university campus, through visits to the four departments, the entrance gateways and the library of the UNEB Campus I. The activity plan involved a previous study of the theoretical framework that underpinned the research, site visit, measurements, interview, photographic record, article writing and seminar presentation discussing the results of the fieldwork. The results presented by the students showed the groups' engagement in carrying out the experience, as well as a greater understanding of the topic addressed in the activity through the theory-practice relationship.
\end{abstract}

Keywords: Active Learning. Accessibility. Engineering. Teaching practice. University. 